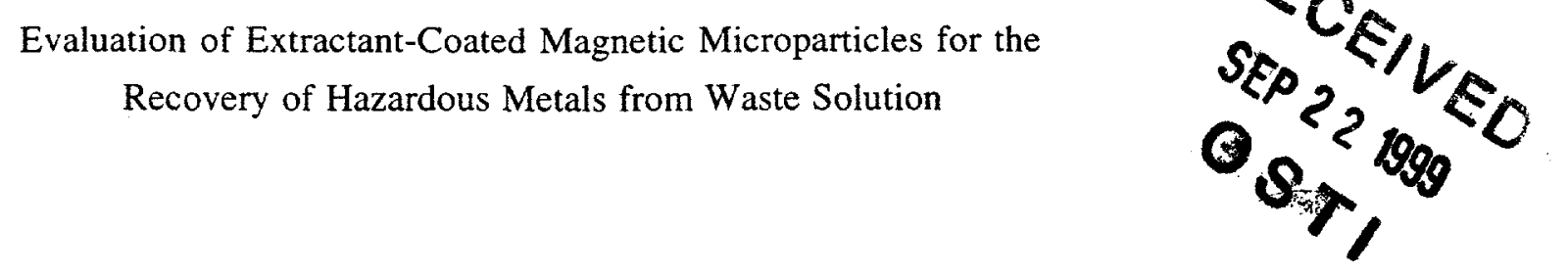

\author{
M. D. Kaminski \\ University of Illinois \\ Department of Nuclear Engineering \\ 103 South Goodwin Avenue \\ Urbana, IL 61801 \\ L. Nuñez and A. E. Visser \\ Chemical Technology Division \\ Argonne National Laboratory \\ 9700 South Cass Avenue \\ Argonne, IL 60439
}

The submitted manuscript has been authored
by a contractor of the U. S. Government
under contract No. W-31-109-ENG-38.
Accordingly, the U. S. Government
retains a non-exclusive, royalty-free
license to publish or reproduce the
published form of this contribution, or
allow others to do so, for U. S.
Government purposes.

Paper submitted for publication in the journal Separation Science and Technology as part of the issue devoted to the proceedings of the "Tenth Symposium on Separation Science and Technology for Energy Applications," Gatlinburg, Tennessee, October 20-24, 1997. 


\section{DISCLAIMER}

This report was prepared as an account of work sponsored by an agency of the United States Government. Neither the United States Government nor any agency thereof, nor any of their employees, make any warranty, express or implied, or assumes any legal liability or responsibility for the accuracy, completeness, or usefuiness of any information, apparatus, product, or process disclosed, or represents that its use would not infringe privately owned rights. Reference herein to any specific commercial product, process, or service by trade name, trademark, manufacturer, or otherwise does not necessarily constitute or imply its endorsement, recommendation, or favoring by the United States Government or any agency thereof. The views and opinions of authors expressed herein do not necessarily state or reflect those of the United States Government or any agency thereof. 


\section{DISCLAIMER}

Portions of this document may be illegible in electronic image products. Images are produced from the best available original document. 


\title{
Evaluation of Extractant-Coated Magnetic Microparticles for the \\ Recovery of Hazardous Metals from Waste Solution
}

\author{
M. D. Kaminski \\ University of Illinois \\ Department of Nuclear Engineering \\ 103 South Goodwin Avenue \\ Urbana, IL 61801 \\ L. Nuñez and A. E. Visser \\ Chemical Technology Division \\ Argonne National Laboratory \\ 9700 South Cass Avenue \\ Argonne, IL 60439
}

\begin{abstract}
A magnetically assisted chemical separation (MACS) process was developed earlier at Argonne National Laboratory (ANL). This compact process was designed for the separation of transuranics (TRU) and radionuclides from the liquid waste streams that exist at many DOE sites, with an overall reduction in waste volume requiring disposal. The MACS process combines the selectivity afforded by solvent extractant/ion exchange materials with magnetic separation to provide an efficient chemical separation. Recently, the MACS process has been evaluated with acidic organophosphorus extractants for hazardous metal recovery from waste solutions. Moreover, process scale-up design issues have been addressed with respect to particle filtration and recovery.

Two acidic organophosphorus compounds have been investigated for hazardous metal recovery, bis(2,4,4-trimethylpentyl) phosphinic acid (Cyanex® 272) and bis(2,4,4trimethylpentyl) dithiophosphinic acid (Cyanex ${ }^{\circledR}$ 301). Coated onto magnetic microparticles, these extractants demonstrated superior recovery of hazardous metals from solution, relative to what was expected on the basis of results from solvent extraction experiments. The results illustrate the diverse applications of MACS technology for dilute waste streams. Preliminary process scale-up experiments with a high-gradient magnetic separator at Oak Ridge National Laboratory have revealed that very low microparticle loss rates are possible.
\end{abstract}




\section{INTRODUCTION}

The use of the neutral organophosphorus extractants octyl(phenyl)-N,Ndiisobutylcarbanoyl methyl phosphine oxide (CMPO) and tributyl phosphate (TBP), coated onto ferromagnetic microparticles has been evaluated for the extraction of TRU metals from acidic solutions (1). In that study, higher distribution coefficients were obtained for Am(III) and Pu(IV) extraction with CMPO-TBP-coated microparticles than were expected from liquid-liquid separation results under similar conditions. The study implied that a synergistic effect existed in this system, unlike what was expected from typical solvent extraction recovery systems $(1,2)$. The identification of the synergistic effect has been difficult because of the chemical complexity of the microparticles support (mean diameter $=0.88 \mu \mathrm{m}$ ), which is composed of iron oxide, charcoal, and $\mathrm{N}, \mathrm{N}$-methylene bis-acrylamide polymer. With the observed synergism, the application of metal recovery systems to very dilute solutions becomes attractive. Extractant-coated microparticles offers other advantages that are worthy of further investigation. Separation of phases and subsequent recovery of metal concentrate are facilitated by the absence of such problems as crud formation and solvent lósses.' From an engineering standpoint, a magnetic filtration system offers a simple, compact, and costeffective processing unit that can be easily tailored to specific processing goals.

The use of extractant-coated magnetic microparticles has been extended to the evaluation of hazardous metal extraction with commercially available bis $(2,4,4-$ trimethylpentyl) phosphinic acid (Cyanex ${ }^{\circledR}$ 272) and bis(2,4,4-trimethylpentyl) dithiophosphinic acid (Cyanex $® 301)$, as in previous studies $(1,2)$. Specifically, this paper presents results from cadmium and zinc recovery with the same polymeric support and compares the separation efficiency with solvent extraction measurements in the literature.

In considering the success of extractant-coated magnetic microparticles, preliminary process engineering issues were addressed. The small size of these particles precludes the use of conventional filtration and recovery systems. Therefore, magnetic separation is the targeted filtration concept. For this paper, magnetic field requirements and flow rate limitations were addressed by testing a high-gradient magnetic separator at Oak Ridge National Laboratory (ORNL).

\footnotetext{
${ }^{1}$ Operating plants with Cyanex 272 report solvent losses of $10-15 \%$ from solubility and entrainment.
} 


\section{CMPO-TBP Systems}

Previous studies (1) showed that coatings on magnetic microparticles with $0.75 \underline{\mathrm{M}}$ CMPO in undiluted TBP had a partition coefficient $\left(K_{d}\right)$ of $3000-5000 \mathrm{~mL} / \mathrm{g}$ for Am. With the same concentration of extractants, a volume distribution ratio (D) of 240 was obtained with a solvent extraction system having an aqueous-to-organic ratio $(\mathrm{A} / \mathrm{O})$ of 1 . On the basis of these experimentally measured $\mathrm{D}$ values and the cubic dependence on the CMPO concentration, the predicted (2) $\mathrm{K}_{\mathrm{d}}$ values are about $80 \mathrm{~mL} / \mathrm{g}$, in contrast to the $3000-5000 \mathrm{~mL} / \mathrm{g}$ obtained experimentally. Similar behavior was observed with partition coefficients $(5000-10,000 \mathrm{~mL} / \mathrm{g})$ for $\mathrm{Pu}$, which are much higher than predicted by solvent extraction measurements (2). The batch extraction results suggested a synergism between the solvent and complex microparticle support. Exactly how the support influences the metalligand separation remains unknown.

\section{Support-Extractant Interactions}

Support-extractant interactions have been identified in previous investigations. Hydrometallurgy studies on solvent extractants impregnated into polymeric supports have identified the possible role of the polymeric support in the extraction of heavy metals (3-5). Also, Alexandratos and Miller (6) pointed out the influence of a polymeric support on the efficacy of covalently bonded (dialkylamino) pyridine ligands. The efficacy was maximized when the functionalization was less than $50 \%$ due to an increased hydrophobicity surrounding each ligand. Their study suggested that the microenvironment surrounding the extractant played a role in metal-extractant complexation. Studies have established the influence of the polymeric support on the ligand-molecule interactions, postulating that the polymeric support provided mechanisms that enhance the ligand specificity toward the metal ion $(7,8)$. Furthermore, polymeric supports containing two different ligands can act in a cooperative manner to yield a higher level of complexation than can be attained from either ligand alone. This selectivity is obtained by an access mechanism that serves to bring the metal ions into the polymeric support in a cooperative fashion (9). One example of this cooperative mechanism is a bifunctional polymer containing a phosphinic acid and quaternary ammonium salt (10). The synergistic cooperation allows one ligand to bring the metal ion near the second ligand, which interacts selectively with the metal ion. This mechanism can also serve to dehydrate the metal ions (e.g., actinides), which thermodynamically (11) favors the metal-extractant complexation. Although the currently studied system has only one functional group on the support [acrylamide, $-\mathrm{CH}_{2} \mathrm{CH}\left(\mathrm{CONH}_{2}\right)$ ], the sorption of extractants on the microparticle can produce multifunctionality with the other matrix components. The actinides have both soft and hard characteristics (12), and the currently used $\mathrm{N}, \mathrm{N}$-methylene bis-acrylamide polymer provides a preorganization of soft and hard donor sites in near proximity that can aid in hydrogen bonding. Furthermore, the 
nitrogen in an amide has some characteristics of the ammonium ion, except that the amides are far less basic. Thus, the sorption of the organophosphorus extractant onto the polymer support would increase the functionality of the microparticle. In addition, the interactions of the iron oxide and charcoal can affect the orientation of the metal ion and possibly aid in bringing it closer to the selective extractant. Systematic studies of extractants other than CMPO and TBP provide some information about the effect that the complex support may have on the separation of transuranic and hazardous metals from solution.

\section{EXPERIMENTAL}

\section{Reagents and Equipment}

Metals were obtained as A.C.S.-grade sulfate salts. Stock solutions were prepared by diluting concentrated solutions. ${ }^{2}$ The $\mathrm{pH}$ was adjusted with microliter quantities of dilute $\mathrm{H}_{2} \mathrm{SO}_{4}$ and monitored with an Accumet ${ }^{\mathrm{TM}}$ Model $10 \mathrm{pH}$ meter from Fisher Scientific. The Cyanex 272 and 301 solvents were obtained from American Cyanamid Co. and the di-(2-ethylhexyl) phosphoric acid ( $\mathrm{D}_{2}$ EHPA) from Aldrich Chemical Co. (97\% pure) without further purification. The extractants were prepared by dissolving the appropriate amount in $0.5 \mathrm{M} \mathrm{D}_{2} \mathrm{EHPA}$ and ethanol. All the radiotracers were obtained from the Chemical Technology Division at Argonne National Laboratory. Metal analysis was done with inductively coupled plasma-atomic emission spectroscopy (ICP-AES). The ferromagnetic microparticles consist of equal parts of $\mathrm{N}, \mathrm{N}$-methylene bis-acrylamide $\left[\left(\mathrm{H}_{2} \mathrm{C}=\mathrm{CHCONH}\right)_{2} \mathrm{CH}_{2}\right]$, iron oxide, ${ }^{3}$ and charcoal (Cortex Biochem, Inc.). Microparticle sizes ranged between 0.1 and $25 \mu \mathrm{m}$, with an average apparent diameter of $0.88 \mu \mathrm{m}$. Coated microparticles were prepared as described previously, with an extractant-microparticle ratio of $2.5 \mathrm{~mL}: 1 \mathrm{~g}$. Ethanol was used as the volatile diluent (13).

\section{PROCEDURE}

\section{Measurements of Equilibrium Partition Coefficient}

Contacts were performed in test-tube experiments with $2 \mathrm{~mL}$ of metal solution and approximately $3 \mathrm{mg}$ of microparticles. The $\mathrm{pH}$ was adjusted by adding microliter quantities of dilute sulfuric acid. The test tubes were placed in an ultrasonic bath for $3-5 \mathrm{~min}$ to promote microparticle dispersion. Then, the samples were mixed vigorously for $3 \mathrm{~min}$ and placed in a $25^{\circ} \mathrm{C}$ bath for $3 \mathrm{~min}$. This step was repeated twice more before the test tubes were

\footnotetext{
${ }^{2}$ Approximately 5 and $10 \mathrm{ppm}$ for $\mathrm{Cd}(\mathrm{II})$ and $\mathrm{Zn}(\mathrm{II})$, respectively.

${ }^{3}$ The ferromagnetic microparticles will be referred to as magnetic microparticles.
} 
placed in a magnetic rack, where permanent magnets in the wall cause the particles to aggregate to one side of the test tube. The supernatant was withdrawn, and the $\mathrm{pH}$ was measured and the solution diluted with deionized water for ICP-AES analysis or prepared for gamma or liquid scintillation analysis. The equilibrium partition coefficient, $\mathrm{K}_{\mathrm{d}}$, is expressed in Eq. 1 as,

$$
K_{d}=\frac{V}{m} \frac{\left(C_{i}-C_{f}\right)}{C_{f}}
$$

where $\mathrm{V}$ is the volume of the aqueous phase, $\mathrm{m}$ is the mass of microparticles, and $\mathrm{C}_{\mathrm{i}}$ and $\mathrm{C}_{\mathrm{i}}$ are aqueous metal concentration before and after microparticle contact, respectively.

\section{Magnetic Filtration Experiments}

Bench-scale magnetic filtration experiments were conducted at ORNL with uncoated magnetic microparticles. Prior to flocculation the microparticles were washed free of preservatives with deionized water several times and dried. Flocculation occurred in a standard stirred cell of 100-mm diameter and 142.2-mm height, and equipped with four baffles, each $10-\mathrm{mm}$ wide. The initial volume of the suspension used in each experiment was $0.6 \mathrm{~L}$, with a flow rate between 6 and $51 \mathrm{~L} / \mathrm{h}$. The magnetic filtration process was started 5 or $10 \mathrm{~min}$ after flocculation was initiated and ranged in magnetic field from 0.1 to $0.8 \mathrm{~T}$. Additional details are provided elsewhere (14).

\section{RESULTS AND DISCUSSION}

\section{TRU Separation}

In order to quantify the efficiency of extractant-coated microparticles, our experimental results were compared to data from the solvent extraction literature. The partition coefficients, $K_{d}$, were converted to volume distribution ratios, $D$, with conversion factors similar to those used in extraction chromatography, where the density and weight percent of the extractant sorbed on the resin are incorporated into the conversion factor (15). Magnetic microparticles were generally loaded to approximately $30 \%$ for CMPO-TBP and $1-5 \%$ for other extractants tested to date. These loadings generate a conversion factor of approximately 3 for CMPO-TBP particles and approximately 25 for other extractant-coated microparticles. In comparison, typical extraction chromatography resins are loaded to 10-40\%. Partition $\left(\mathrm{K}_{\mathrm{d}}\right)$ results from magnetic microparticle measurements with CMPO-TBP are presented elsewhere (2), but they are summarized, along with the calculated distribution ratios $\left(D_{\text {calc }}\right)$, in Table 1 . The relative efficiency, $\varepsilon$, is defined here as the ratio of $D_{\text {calc }}$ to the solvent extraction distribution ratio, $D_{\mathrm{sx}}$. The relative efficiency for americium separation is 
7-8.8, and that for plutonium separation is $39-49$, for the systems tested. The MACS particles coated with CMPO-TBP display a superior separation of americium and plutonium with respect to that expected from solvent extraction experiments. Therefore, it is postulated that a synergistic effect may exist between the extractant and the particle material.

Table 1. Americium and plutonium distribution ratios, $D_{s x}$, partition coefficients, $K_{d}$, and calculated distribution ratios, $\mathrm{D}_{\text {calc }}$, for CMPO-TBP-coated microparticles. Data taken from (2), except where indicated.

\begin{tabular}{|c|c|c|c|c|c|c|}
\hline $\begin{array}{l}\text { TRU } \\
\text { Metal }\end{array}$ & $\begin{array}{c}\text { CMPO } \\
\text { Conc. (M) }\end{array}$ & Acid & $\mathrm{D}_{\mathrm{sx}}$ & $\mathrm{K}_{\mathrm{d}}(\mathrm{mL} / \mathrm{g})$ & $\mathrm{D}_{\text {calc }}$ & $\varepsilon$ \\
\hline$\overline{A m}$ & $1.2 \mathrm{M}$ & $4.9 \mathrm{M} \mathrm{HNO}_{3}$ & $1200^{*}$ & 2790 & 8370 & 7.0 \\
\hline Am & $1.2 \mathrm{M}$ & $2 \mathrm{M} \mathrm{HNO}_{3}$ & 1700 & $4000-5000$ & $12,000-15,000$ & $7.1-8.8$ \\
\hline $\mathrm{Pu}$ & $1.0 \mathrm{M}$ & PFP** & 1400 & 18,000 & 54,000 & 39 \\
\hline $\mathrm{Pu}$ & $1.0 \mathrm{M}$ & $8.0 \mathrm{M} \mathrm{HCl}$ & 1600 & 26,000 & 78,000 & 49 \\
\hline
\end{tabular}

*Extrapolated from Ref. 16. ${ }^{* *}$ Plutonium Finishing Plant Simulant.

A possible explanation for the observed synergism may be the occurrence of extractant preorganization with the polymeric support, as mentioned earlier. The microparticle constituents (either the charcoal, iron oxide, or N,N-methylene bis-acrylamide polymer) may interact with the metal, either by dehydrating or partially dehydrating the metal or by retaining the metal in the proximity of the extractant until the extractant-metal reaction can take place. Sorption onto the charcoal by the chain group of the extractant would make the extraction independent of chain length. It is unclear how the iron oxide interacts with the extractant or aids in the separation. However, actinides and other radionuclides are known to sorb onto iron oxides, especially at alkaline $\mathrm{pH}$ values $(17,18)$. Studies of the uncoated polymeric support showed negligible partition of the metal onto the magnetic microparticles. If the polymeric support aids in extraction, one would expect that excessive solvent loading on the particle, with subsequent nonparticipation by the support, would decrease the synergistic effect. This is precisely what has been observed $(1,13)$. These trends show that there is an optimal amount of extractant necessary for the highest efficiency in separation. Also, the reduction in the partition coefficient above the optimal amount may be partly attributable to the increase in aqueous solubility of the extractant (19).

\section{Hazardous Metal Recovery}

The commercially available extractants Cyanex 272 and Cyanex 301 were chosen because of their importance in industrial applications and their low aqueous solubility. The overall reaction for divalent extraction by acidic organophosphorus reagents occurs according to the reaction, 


$$
M^{2+}+\overline{(p+2)(H X)} \stackrel{\beta_{2 p}}{\longrightarrow} \overline{M X_{2}(H X)_{p}}+2 H^{+}
$$

where the overbar denotes the organic phase species, HX denotes the extractant and $\beta_{2 p}$, the equilibrium constant (20). For extraction by Cyanex 272, $\mathrm{p}=2$ for $\mathrm{Cu}, \mathrm{p}=2$ and $\mathrm{p}=1$ for $\mathrm{Zn}$, and $\mathrm{p}=2$ and $\mathrm{p}=3$ for $\mathrm{Cd}(20)$. Following from above, the graphical analysis of $\log \mathrm{K}_{\mathrm{d}}$ vs. $\mathrm{pH}$ plots should produce data lines of slope 2 to correspond with the thermodynamic reaction (Eq. 2).

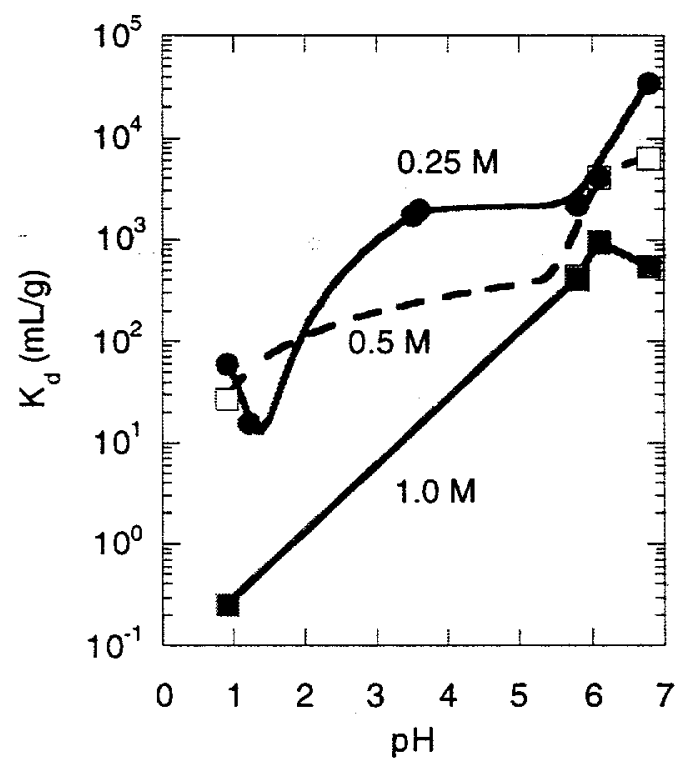

Figure 1. Concentration dependence for zinc recovery with microparticles coated with $0.25,0.5$, and $1.0 \underline{\mathrm{M}}$ Cyanex 272 and $0.5 \mathrm{M} \mathrm{D}_{2}$ EHPA diluted by ethanol at $20^{\circ} \mathrm{C}$.

Initially, microparticles were prepared by sorbing a mixture of $0.25,0.5$, or $1.0 \underline{\mathrm{M}}$ Cyanex solvent in $0.5 \mathrm{M} \mathrm{D} \mathrm{D}_{2} \mathrm{EHPA}$ and diluting with ethanol. Figure 1 gives concentration dependence curves for zinc recovery by microparticles coated with Cyanex $272,{ }^{4}$ and is representative of all extractants tested to date. Also, since the coating process has not been optimized, data scatter is observed. The $K_{d}$ values decrease as a function of increased extractant concentration, which is contrary to solvent extraction studies (20). With consistency, partitioning was favored for microparticles prepared with the more dilute solvent. This is also consistent with previous coatings prepared with a variation of the TRUEX (TRansUranic EXtraction) solvent (13), where increased CMPO loading reduced TRU

\footnotetext{
${ }^{4}$ Curve fits expressed herein are smooth correlations and not least-squares fits.
} 
partition coefficients. This may be a direct result of the diminishing role (synergism) of the microparticle support when the solvent is overloaded on the support.

\section{Cyanex 272}

Cyanex 272, bis $(2,4,4$-trimethylpentyl) phosphinic acid, is a well-known extractant that has received much attention in the selective recovery of cobalt over nickel from sulfate and chloride media, and the recovery of other notable hazardous metals (e.g., $\mathrm{Zn}, \mathrm{Cu}$, and $\mathrm{Cd}$ ) over alkaline earths, such as calcium (21). The latter feature is highly advantageous for industrial applications because of loading considerations and subsequent gypsum formation upon stripping (21). The behavior of microparticles coated with Cyanex 272 with respect to $\mathrm{Cd}(\mathrm{II})$ and $\mathrm{Zn}(\mathrm{II})$ recovery is displayed in Figures 2 and 3.

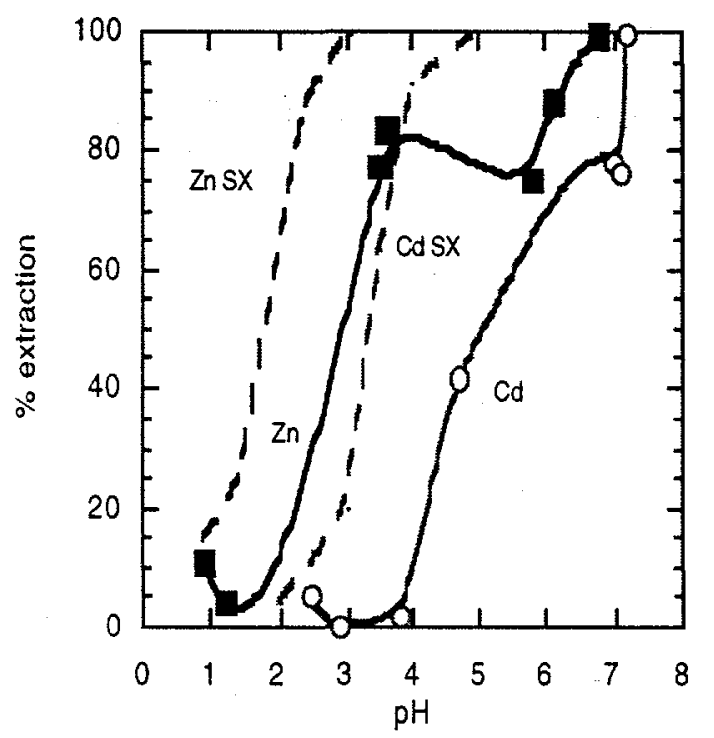

Figure 2. Extraction of $\mathrm{Zn}$ (II) and $\mathrm{Cd}$ (II) as a function of $\mathrm{pH}$. Microparticles were coated with $0.25 \mathrm{M}$ Cyanex 272 and $0.5 \mathrm{M} \mathrm{D}_{2}$ EHPA diluted by ethanol at $20^{\circ} \mathrm{C}$. Solvent extraction (SX) was performed with $0.6 \mathrm{M}$ Cyanex 272 and 10 vol. \% p-nonylphenol in Kermac $470 \mathrm{~B}$ diluent at $50^{\circ} \mathrm{C}$ and $\mathrm{O} / \mathrm{A}=1(2 \overline{1}, 22)$.

Figure 2 shows the percent extraction for $\mathrm{Zn}(\mathrm{II})$ and $\mathrm{Cd}(\mathrm{II})$ with the coated microparticles and the reported solvent extraction data $(21,22)$. Zinc is extracted well at pH $>4$ while $\mathrm{Cd}(\mathrm{II})$ is extracted at $\mathrm{pH}>6$. Solvent extraction measurements indicate that nearly complete extraction of $\mathrm{Zn}(\mathrm{II})$ and $\mathrm{Cd}(\mathrm{II})$ occurs at $\mathrm{pH}>3$ and $\mathrm{pH}>4$, respectively, as indicated by the dashed lines in Figure 2. The shift is probably due to differences in the organic-phase composition (diluent). 


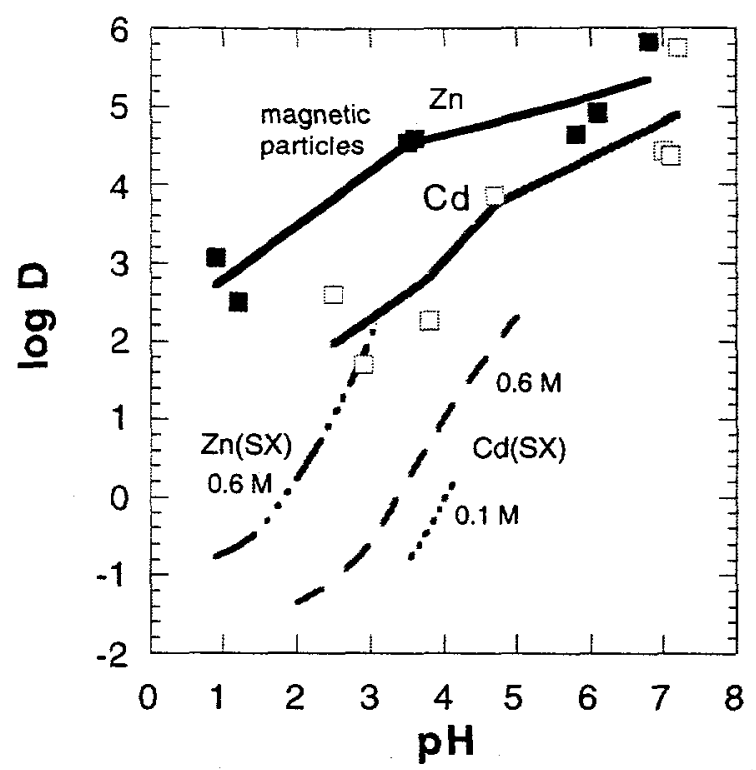

Figure 3. Equivalent distribution ratio for $\mathrm{Zn}(\mathrm{II})$ and $\mathrm{Cd}(\mathrm{II})$ with microparticles coated with $0.25 \mathrm{M}$ Cyanex 272 and $0.5 \mathrm{M} \mathrm{D}$ EHPA diluted by ethanol at $20^{\circ} \mathrm{C}$. Solvent extraction data (SX) were borrowed from three sources. The $0.6 \mathrm{M}$ Cyanex 272 data were obtained with the extractant in 10 vol. \% p-nonylphenol in Kermac 470B diluent and $0.015 \mathrm{M}$ metal with $\mathrm{O} / \mathrm{A}=1(21,22)$. The $0.1 \mathrm{M}$ Cyanex 272 data were obtained with the extractant in Isopar- $\mathrm{H}$ and $10^{-4} \underline{\mathrm{M}}$ metal with $\overline{\mathrm{O}} \mathrm{A}=1(20)$.

Figure 3 illustrates the partition coefficients (converted to volume distribution ratios) associated with magnetic microparticles and includes solvent extraction data from Sastre et al. (20), American Cyanamid (21), and Rickelton (22). Slope analyses of the above data were hindered by curvature of the data above $\mathrm{pH} \sim 4$ and high degrees of uncertainty associated with the analyses of the very dilute solutions. This problem is especially evident at low $\mathrm{pH}$, where small variations in the metal concentration can translate to order-of-magnitude differences in the calculated $K_{d}$ and, consequently, flattened curves translate into a slope of 0.8 and not the 2 expected from the solvent extraction studies (20). Nevertheless, the above data illustrate the superior extraction capabilities of microparticles coated with Cyanex 272 and $D_{2} E H P A$, as opposed to conventional solvent extraction systems, for the recovery of zinc and cadmium.

\section{Cyanex 301}

Cyanex 301, bis (2,4,4-trimethylpentyl) dithiophosphinic acid, has a sulfur atom as the anionic donor atom, which increases the acidity and thereby facilitates extraction of metals at low $\mathrm{pH}$ values. Cyanex 301 has been shown to be less selective between transition metals at low $\mathrm{pH}(<2)$ but extremely selective between heavy metals and alkaline earths. It 
displays a greater selectivity for zinc over calcium than does Cyanex 272 (21). It has received attention as a possible replacement for Cyanex 272 for recovery of cobalt from nickel sulfate solutions.

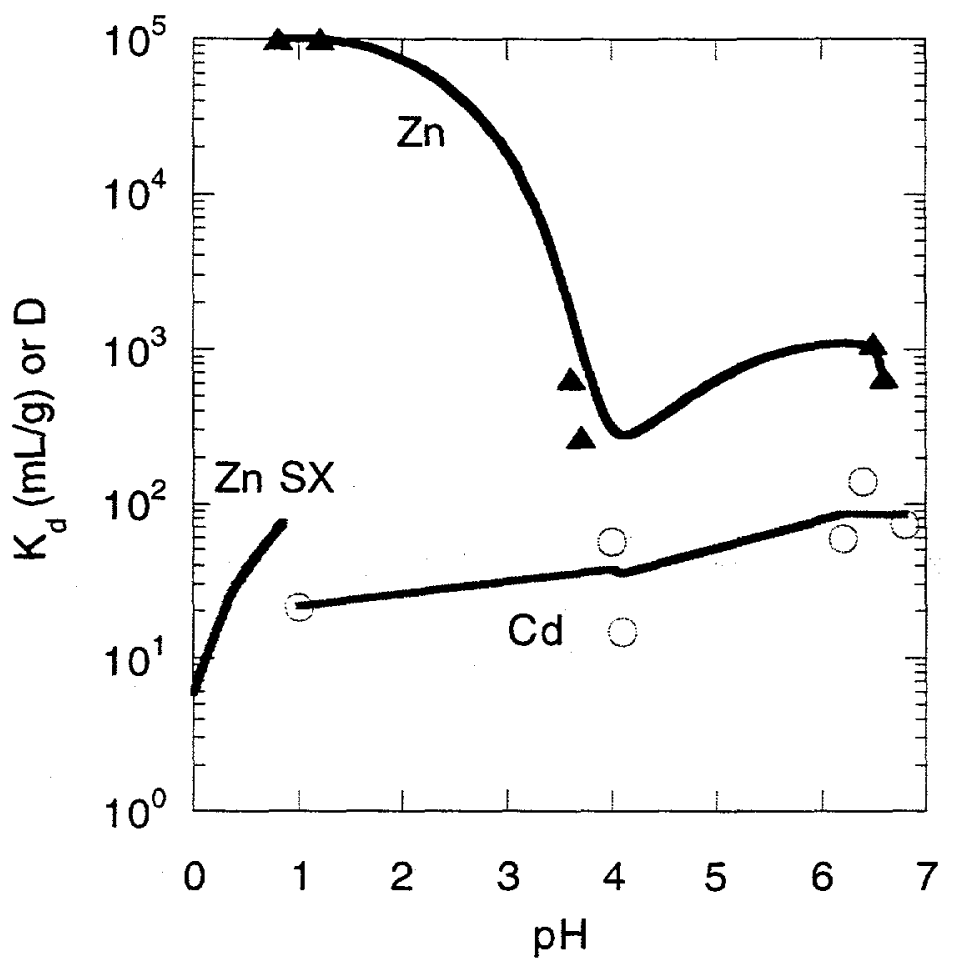

Figure 4. Partition coefficient curves versus $\mathrm{pH}$ for recovery $\mathrm{Zn}(\mathrm{II})$ and $\mathrm{Cd}(\mathrm{II})$ with microparticles coated with $0.25 \mathrm{M}$ Cyanex 301 and $0.5 \mathrm{M} \mathrm{D}_{2}$ EHPA diluted by ethanol at $20^{\circ} \mathrm{C}$. Solvent extraction (SX) distribution ratio data from Sole and Hiskey (24) were collected for $1 \mathrm{mM} \mathrm{ZnSO}_{4}$ in $0.5 \mathrm{M} \mathrm{Na}_{2} \mathrm{SO}_{4}$ with $0.1 \mathrm{M}$ Cyanex 301 in xylene and O/A $=0.5$.

Figure 4 shows that $\mathrm{Cd}(\mathrm{II})$ does not extract well in acidic to neutral media. This is rather surprising, considering the soft character of $\mathrm{Cd}$ (II) and the softness of the donor sulfur. Although no cadmium data were available for direct comparison, 5\% Cyanex 301 in dodecane is known to quantitatively remove $100 \mathrm{mg} / \mathrm{L}$ of $\mathrm{Cd}(\mathrm{II})$ at $\mathrm{pH} 1$ (23). Also, it has been shown to remove $\mathrm{Cd}$ (II) from wet process phosphoric acid (25). The data on $\mathrm{Zn}$ (II) extraction show similarities to solvent extraction data from American Cyanamid (21), which reports quantitative extraction of $\mathrm{Zn}(\mathrm{II})$ at $\mathrm{pH}<2.3$. However, slope analysis was difficult because of the low $\mathrm{pH}$ of extraction (24). According to Sole and Hiskey. (24), extraction of $\mathrm{Zn}$ (II) from sulfate media follows as expected from Eq. 2. These data are presented in Figure 4 for comparative purposes. The increased extraction efficiency with magnetic particles is evident. 


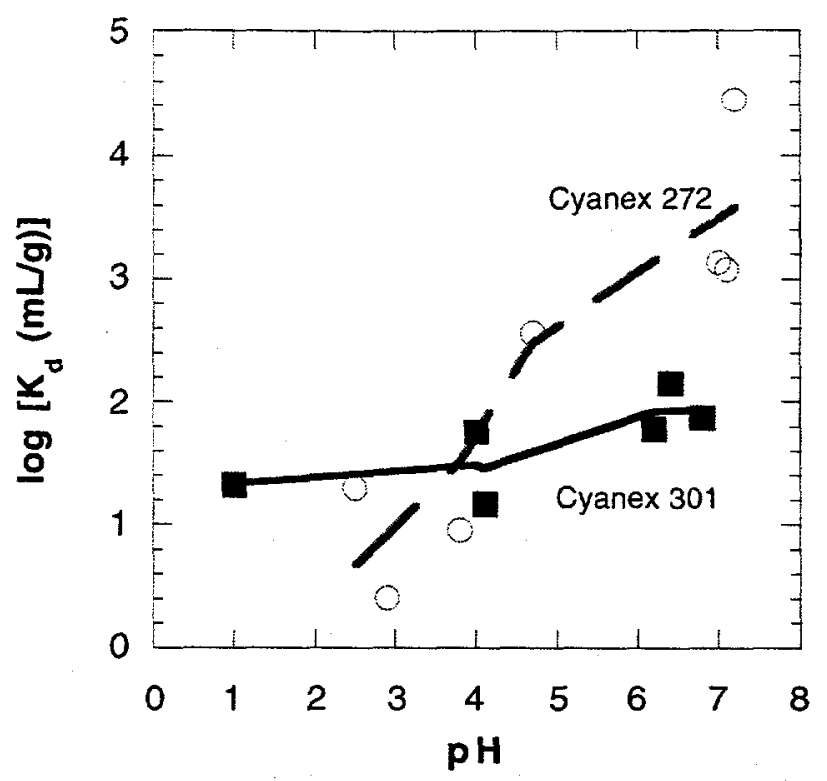

Figure 5. Cadmium(II) partition coefficient curves with microparticles coated with $0.25 \mathrm{M}$ Cyanex 272 and 301 and $0.5 \mathrm{M} \mathrm{D}$ EHPA diluted by ethanol at $20^{\circ} \mathrm{C}$. Note that the ordinate axis is expressed in log format.

With regard to recovering $\mathrm{Cd}$, Figure 5 illustrates that Cyanex 301 is more effective than Cyanex 272 at $\mathrm{pH}<3.5$, while at higher $\mathrm{pH}$, Cyanex 272 is more effective. For $\mathrm{Zn}$ recovery, as presented in Figure 6, Cyanex 301 is highly effective at $\mathrm{pH}<3$, while at higher $\mathrm{pH}$, Cyanex 272 is more effective.

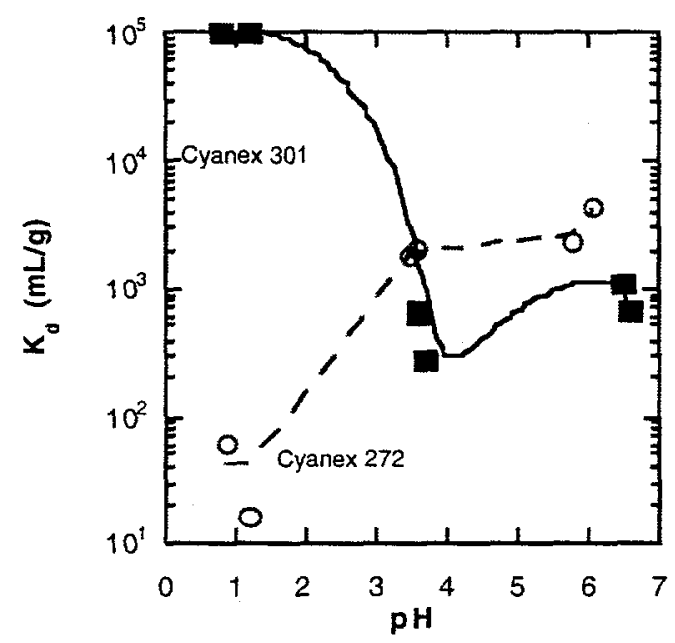

Figure 6. Zinc(II) partition coefficient curves with microparticles coated with $0.25 \mathrm{M}$ Cyanex 272 and 301 and $0.5 \mathrm{M} \mathrm{D}_{2}$ EHPA diluted by ethanol at $20^{\circ} \mathrm{C}$. 
The results obtained on extractant-coated microparticle systems are encouraging. In the current experimental plan, no attempt was made to decouple the contributions from the various magnetic microparticle components. The objective of this study was to identify a similar synergistic effect with a variety of extractants on the same supporting matrix. The synergistic effect was evident for Cyanex 272 extraction of $\mathrm{Zn}(\mathrm{II})$ and $\mathrm{Cd}(\mathrm{II})$ and for Cyanex 301 extraction of $\mathrm{Zn}(\mathrm{II})$. The effectiveness of $\mathrm{Cd}(\mathrm{II})$ extraction with Cyanex 301 could not be ascertained because of the lack of available solvent-extraction distribution measurements for the metal. Future investigations will seek to determine adsorption mechanisms and loading capacities, stripping efficiencies, and solvent losses. In addition, other solventmicroparticle systems will be investigated.

In light of the success that extractant-coated magnetic microparticles have achieved, preliminary engineering aspects were considered. Microparticle loss is the most financially costly issue; the following section addresses microparticle losses with changes in flow rate, magnetic field strength, and filtration geometry.

\section{High-Gradient Magnetic Separation}

The target magnetic filtration process for this separation technology is high-gradient magnetic separation (HGMS). An HGMS system is applicable to a wide range of liquid wastes, including groundwater, process waters, and tank supernatants. As described previously (1), mixing will occur in situ or in a flocculation tank. After the appropriate residence time, the microparticles will be filtered from the waste water with a magnetic filter. An HGMS system at ORNL was used to perform experiments related to the filter efficiency.

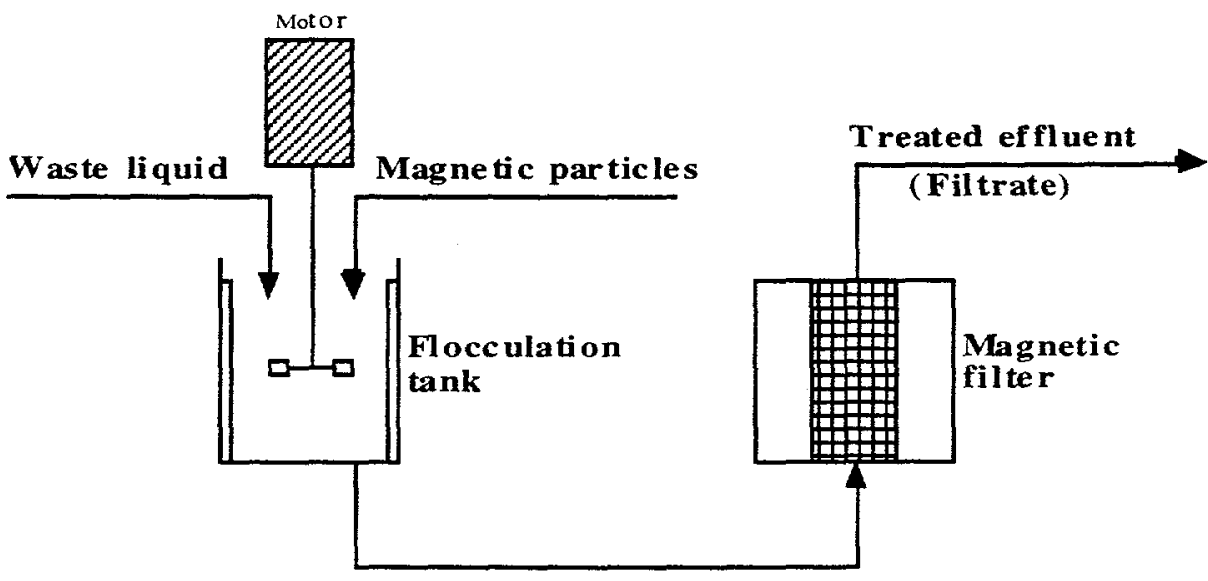

Figure 7. Schematic of magnetic filtration process. 
Six experiments were conducted with uncoated magnetic microparticles. The zeta potential of these microparticles was measured at $-35.1 \mathrm{mV}$ for a solution of $1000 \mathrm{ppm}$ (or $0.1 \mathrm{wt} \%$ ) microparticles in deionized water at $\mathrm{pH} 6$. These microparticles proved to be paramagnetic, with a volume magnetic susceptibility of $5.93 \times 10^{-6}$ in the $1000 \mathrm{ppm}$ solution. At this magnetic susceptibility, even a relatively modest magnetic field of $0.1 \mathrm{~T}$ is capable of removing $98 \%$ of the uncoated magnetic microparticles. At a higher field $(1.5 \mathrm{~T})$ and a low flow rate $(0.6 \mathrm{~L} / \mathrm{h})$, breakthrough was not measurable. The microparticles were retained in the filter and eventually completely blocked the flow with an approximately 26 psi pressure drop.

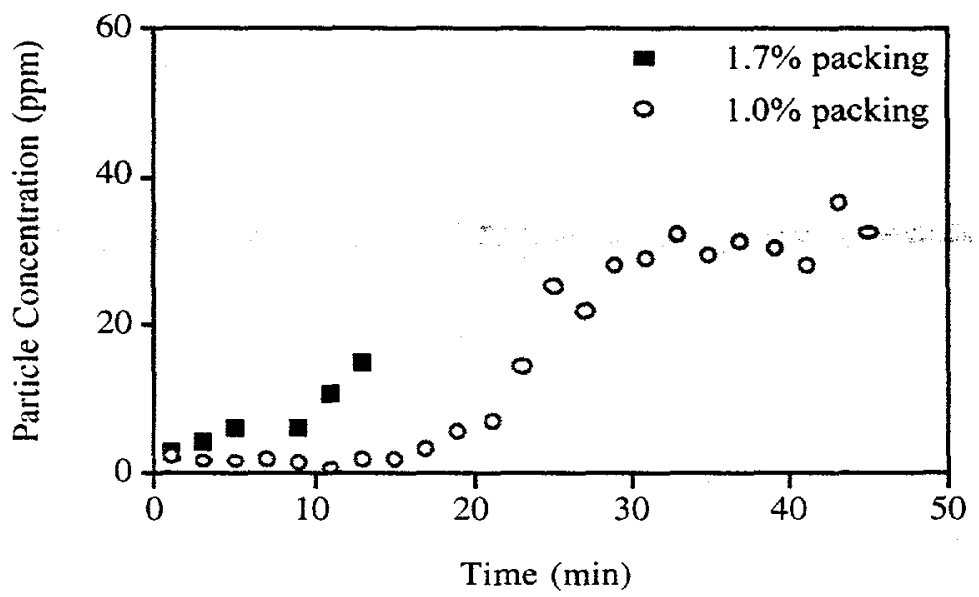

Figure 8. Effect of filter packing density on the breakthrough of uncoated magnetic microparticles. Solution of $100 \mathrm{ppm}$ uncoated magnetic microparticles in deionized water; flow rate, $24 \mathrm{~L} / \mathrm{h}$, magnetic field, $0.8 \mathrm{~T}$.

As expected, a lower magnetic field $(0.1 \mathrm{~T})$ results in an earlier breakthrough of $<10 \mathrm{~min}$ opposed to slightly greater than $20 \mathrm{~min}$ for a magnetic field of $0.8 \mathrm{~T}$. At $0.8 \mathrm{~T}$, the breakthroughs occur at approximately $50 \mathrm{~min}, 20 \mathrm{~min}$, and after a few minutes for flow rates of $11.5,24$, and $51 \mathrm{~L} / \mathrm{h}$, respectively. The leakage rates (prior to breakthrough) were $<2 \%$ in all cases and would be likely to improve with the increased magnetic field expected for scale-up processing. ${ }^{5}$ An interesting result is shown in Figure 8 , where the higher packing density of the filter $(1.7 \%$ ) results in earlier microparticle breakthrough (after about $10 \mathrm{~min}$ ) than for the $1 \%$ packing density (after $20 \mathrm{~min}$ ). This comparison illustrates the contribution of turbulent forces created by the packing. Although local magnetic field gradients are expected to increase as the packing increases, the generation of turbulent flow fields is clearly offsetting the forces generated by the magnetic field. Also of considerable significance, these

\footnotetext{
${ }^{5}$ Target magnetic field strength is between 1 and $2 \mathrm{~T}$ for a scale-up unit.
} 
magnetic microparticles were successfully modeled to calculate the magnetic filtration with a mathematical approach, without empirical fitting coefficients (14).

\section{CONCLUSIONS}

The use of extractant-coated magnetic microparticles has been successful with neutral and acidic organophosphorus extractants. The explanation for augmented partitioning may be interactions between the extractant and the complex iron oxide, N,N-methylene bis-acrylamide, and/or charcoal microparticle support. This paper illustrated the strong partitioning of $\mathrm{Zn}(\mathrm{II})$ and $\mathrm{Cd}(\mathrm{II})$ by Cyanex 272 and $\mathrm{Zn}(\mathrm{II})$ by Cyanex 301 from acidic solution. Although important issues need to be clarified, a synergism was observed with Cyanex 272 and 301 above what was measured or predicted by liquid-liquid systems. Taken together with previous studies these results indicate that a wide range of solvent extraction systems may be improved upon for the recovery of metals from dilute solutions with magnetic microparticles coated by a solvent extractant.

Magnetic filtration experiments show that losses are slight at low magnetic fields and low flow rates and can be predicted with a mathematical breakthrough model. Increasing magnetic field strength offers a method of achieving quantitative recovery of microparticles, while increasing the packing density can be deleterious (depending on the flow characteristics). Future magnetic filtration experiments will focus on separating coated microparticles from actual plating waste solution.

\section{ACKNOWLEDGMENTS}

The authors would like to thank C. Tsouris from Oak Ridge National Laboratory for his assistance with the HGMS experiments.

\section{REFERENCES}

1. Nuñez, L., Buchholz, B. A., and Vandegrift, G. F., "Waste Remediation with In-Situ Magnetically Assisted Chemical Separation," Separation Science and Technology, 30(7-9), 1455-1471, 1995.

2. Nuñez, L., et. al., "Actinide Separation of High-Level Waste with Solvent Extractants on Magnetic Microparticles," Separation Science and Technology, 31(10), 1393-1407, 1996.

3. J. L. Cortina, N. Miralles, M. Aguilar, and A. M. Sastre, "Extraction Studies of Zn(II), $\mathrm{Cu}(\mathrm{II})$, and $\mathrm{Cd}(\mathrm{II})$ with Impregnated and Levextrel Resins Containing Di(2-Ethylhexyl) Phosphoric Acid (Lewatit 1026 Oc)," Hydrometallurgy, 36, 131-142, 1994.

4. J. L. Cortina, N. Miralles, M. Aguilar, and A. M. Sastre, "Solvent Impregnated Resins Containing Di(2-Ethylhexyl) Phosphoric Acid I. Preparation and Study of the Retention and Distribution of the Extractant on the Resin," Solvent Extraction and Ion Exchange, 12(2), 349-369, 1994. 
5. J. L. Cortina, N. Miralles, A. M. Sastre, and M. Aguilar, "Solid-Liquid Extraction Studies of $\mathrm{Zn}(\mathrm{II})$, and $\mathrm{Cd}$ (II) from Chloride Media with Impregnated Resins Containing Mixtures of Organophosphorus Compounds Immobilized onto Amberlite XAD2," Hydrometallurgy, 37, 301-322, 1995.

6. Alexandratos, S. D., and D. H. J. Miller "Microenvironmental Effect in PolymerSupported Reagent. 1. Influence of Copolymer Architecture on the Mitsunobu Reaction," Macromolecules, 29 (25), 1996.

7. S. D. Alexandratos, P. T. Kaiser, and C. E. Grady, "Network Structure as a Variable in Molecular Recognition by Polymer-Supported Reagents," Solvent Extraction and Ion Exchange, 9(2) 309-318, 1991.

8. V. A. Davankov, S. V. Rogozhin, and M. P. Tsyurupa, in Ion Exchange and Solvent Extraction, J. A. Marinssky and Y. Marcus, Eds., Vol. 7, Marcel Dekker, New York, 1977.

9. D. W. Crick and S. D. Alexandratos, "Solid State ${ }^{31} \mathrm{P}$ NMR Characterization of Bifunctional Ion Exchange Resin," Magnetic Resonance in Chemistry, 32 (40-44), 1994.

10. D. W. Crick and S. D. Alexandratos, "Characterization of Bifunctional Interpenetrating Networks via Solid-State ${ }^{13}$ C NMR Spectroscopy," Macromolecule, 26, 3267-3270, 1993.

11. Choppin, G. R., "Use of Physical Chemical Methods to Study Solvent Extraction Systems," in Recent Progress in Actinide Separation Chemistry, Proceedings of the Workshop on Actinide Solution Chemistry, Tokyo, Japan, Sept. 1-2, 1994.

12. J. J. Katz, G. T. Seaborg, and L. R. Morss, Eds., The Chemistry of the Actinide Elements Vol. 1-2, Second Edition, Chapman and Hall Co., pp. 1361-1388, 1986.

13. Buchholz, B. A. et al., "Optimizing the Coating Process of Organic Actinide Extractants on Magnetically Assisted Chemical Separation Microparticles," Separation and Purification Technology, 11, 211-219, 1997.

14. Tsouris, C., et al., "Magnetic-Seeding Filtration," Separation Science and Technology, submitted 1997.

15. Horwitz, E. P., et al., "Separation and Preconcentration of Uranium from Acidic Media by Extraction Chromatography," Analytica Chimica Acta, 266, 25-37, 1992.

16. Horwitz, E. P., and Kalina, D. G., "The Extraction of Am(III) from Nitric Acid by Octyl(phenyl)-N,N-Diisobutylcarbamoylmethylphosphine Oxide - Tri-n-butyl Phosphate Mixtures," Solvent Extraction and Ion Exchange, 2(2), 179-200, 1984.

17. R. L. Kochen, "Actinide Removal from Aqueous Solution with Activated Magnetite," RFP-4100, 1987.

18. S. A. Slater, D. B. Chamberlain, S. A. Aase, B. D. Babcock, C. Conner, J. Sedlet, and G. F. Vandegrift, "Optimization of Magnetite Carrier Precipitation Process for Plutonium Waste Reduction," Separation Science and Technology, 32(1-4), 127-147, 1997.

19 G. Cote, D. Bauer, and S. Esteban, "Solvent Impregnated Resins containing Kelex 100: Aqueous Solubility of Kelex 100 and Distribution Equilibrium of Germanium (IV) Extraction," Ion Exchange Developments and Applications-Proceedings of IEX'96, J. A. Greig, Ed., SCI London, U.K., pp. 363-371 (1996).

20. Sastre. A. M., Miralles, N., and Figuerola, E., "Extraction of Divalent Metals with Bis(2.4,4-Trimethylpentyl) Phosphinic Acid," Solvent Extraction and Ion Exchange, $8(4 \& 5), 597-614,1990$.

21. American Cyanamid Co., CYTEC product portfolio (undated). 
22. Rickelton, W. A., and Boyl, R. J., "The Selective Recovery of Zinc with New Thiophosphinic Acids," Solvent Extraction and Ion Exchange, 8(6), 783-797, 1990.

23. Samar, M., et al., "Purification of Waste Waters Containing Heavy Metals by Surfactant Liquid Membrane Extraction," Proceedings of the International Symposium Hydrometallurgy '94, Institution of Mining and Metallurgy and the Society of Chemical Industry, Cambridge, England, July 11-15, 1994.

24. Sole, K. C., and Hiskey, J. B., "Solvent Extraction Characteristics of Thiosubstituted Organophosphinic Acid Extractants," Hydrometallurgy, 30, 345-365, 1992.

25. Rickelton, W. A., "Novel Uses for Thiophosphinic Acids in Solvent Extraction," JOM, 44(5), 52-54, 1995. 